\title{
Knowledge Management Supremacy in Economic and Managerial Life
}

\author{
Alin Ioan CRETU ${ }^{\star}$, Laurentiu TESCAN ${ }^{\star \star}$, Laurentiu COROBAN ${ }^{\star \star \star}$
}

\begin{tabular}{l}
\hline \multicolumn{1}{c}{ A R T I C L E I N F O } \\
\hline Article history: \\
Accepted June 2019 \\
Available online August 2019 \\
\hline JEL Classification \\
D90, E21, E71, J24 \\
Keywords: \\
Knowledge management, \\
Socialization, Explicit and tacit \\
knowledge, Economic and \\
managerial life
\end{tabular}

\begin{abstract}
A B S T R A C T
Undoubtedly, it is easy to spot that in contemporary society the emphasis on private knowledge became more significant. This type of knowledge has a greater impact on the competitive advantage of a firm than classic factors of production (labor, capital, land). The value of individual or company-level knowledge comes primarily from the fact that it is an intangible asset, and it would be correct to note here that it does not depreciate, but on the contrary, self-generates value continuously. Thus, in the context of rapid globalization and the exponential growth of the IT and communication technologies, the idea of a knowledgebased economy emerged. Opening up the ways to make the knowledge-based economy become reality should currently be on the agenda of every state that wishes to stay competitive in the modern world.
\end{abstract}

(C) 2019 EAI. All rights reserved.

\section{Introduction}

Knowledge management (KM) is defined as a smart way of handling knowledge. On the organizational dimension, KM represents the process of managing organizational knowledge. The goal of KM is to create global value for the operations, and, implicitly, to generate a competitive advantage over competitors. Generating knowledge at the organizational level is essential since this genesis is recognized as the strongest feature of a company, primarily because in favorable conditions it leads to innovation. (I. Nonaka - Knowledge Creation, 1996)

The concept of Knowledge Management and its international certification represents a set of specific competencies and technical consulting and training skills which are based on a US program (Washington DC) started around 1998. The rapid development of the KM concept, guaranteed by the Knowledge Management certification system, allowed in 2004 to found the famous International Knowledge Management Institute (IKMI).

Today IKMI functions as an elite educational institution with a global mission, and as a business association with branches in North America, Europe, Asia, Middle East, Australia, and Africa. IKMI is present in Eastern Europe under the name of Knowledge Management Institute-Romania.

Knowledge Management is the youngest, best known and most innovative channel for training, certification, and, last but not least, international cooperation in the field of management, particularly in the field of global consultancy (branch launched and consolidated at the beginning of this millennium in the United States). Knowledge is an important resource that has a powerful impact on developing the organizational capabilities that would lead to a sustainable competitive advantage (Roja, Nastase, 2013).

One could think of knowledge as of an iceberg: about $20 \%$ of it is above the water, while the greatest $80 \%$-majority is unobservable under the water. The hidden part of the iceberg represents the tacit knowledge. The base idea of KM and the core efforts of a KM specialist aim to transform tacit knowledge into explicit knowledge, in other words, to bring it to the surface as much as it is possible.

\section{On the SECI model of knowledge management - Nonaka-Takeuchi}

The Nonaka-Takeuchi model is a knowledge management model that can be used to generate and convert knowledge. Any given KM model essentially represents the ways of handling knowledge among people, as well as the process of the organization itself. The organization captures and then encodes or generates tangible and/or intangible knowledge in the above-mentioned form, namely explicit or tacit knowledge.

\footnotetext{
${ }^{\star},{ }^{\star \star}$ The Bucharest University of Economic Studies, Romania, ${ }^{\star \star \star}$ Western University of Timisoara, Romania. E-mail addresses: cretu.alinioan@yahoo.com, laurentiu_tescan@yahoo.com, dorucoroban@yahoo.com.
} 
As demonstrated previously, tacit knowledge represents the unwritten kind of knowledge that is used only by verbalizing knowledge and observing carefully the transmitted information. This peculiarity could lead to various perception difficulties for other parties since, unfortunately, there is no written information of any kind that could be later read and analyzed over a longer period of time.

Only the person possessing that knowledge can keep it and use it further on, the information itself remains stored only in their mind. This leads to the idea that explicit knowledge - the clear and replicable kind of knowledge - is the reverse definition of tacit knowledge. In other words, explicit knowledge is the kind of knowledge that is passed on and retained in written form. This knowledge can be used by other people, though not always and not all knowledge is passed on strictly in written form.

The SECI (Socialization-Externalization-Combining-Internalization) management model elaborated by Nonaka and Takeuchi represents possible knowledge transformations, either from tacit to explicit or viceversa from explicit to tacit. Below we reproduce the model of Nonaka and Takeuchi:

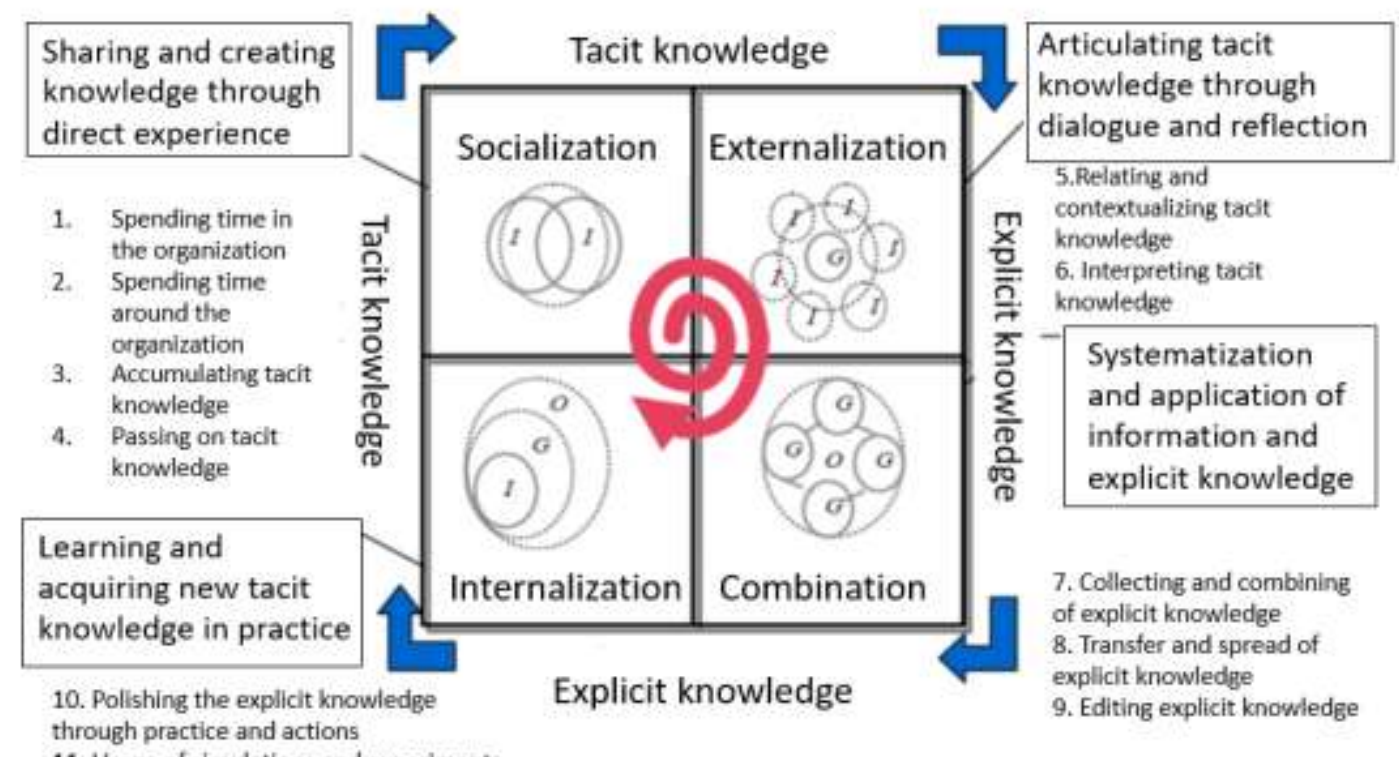
of dynamic knowledge creation, Long Range Planning, vol 33.

Figure 1. The $\mathrm{SECl}$ model for creation and usage of knowledge

As we can see from the figure above, there are four types of explicit and tacit knowledge conversion. Further on we elaborate on each type separately and provide basic examples.

Socialization represents the process of one-sided transmission of tacit knowledge, but not in a concrete way, rather via various common experiences. Since tacit knowledge is always context-dependent, shared experiences and performance of common activities with the people possessing the tacit knowledge is the secret key-ingredient to the successful passing and acquisition of the tacit knowledge.

A good example is a classic job and life relationship model "mentor-mentee". The mentee understands and picks up the skill by directly observing and imitating the actions of his mentor, enriching thus their knowledge by practice, not by reading or talking about the subject.

The quality of the relationship between participants of common experiences is certainly a key factor in the success of knowledge transfer. An insincere or, even worse, an undesired by any of the parties relationship is likely to lead to total failure.

Externalization is the process of replicating tacit knowledge in the form of explicit knowledge. This step together with knowledge creation is the most important among all four since it leads to the rapid formation of new valuable knowledge and valuable key concepts. After tacit knowledge gets reshaped into means that can be communicated to others, it becomes the base element for a new upcoming chain of knowledge.

Daily meetings are a classical example of externalization. Employees seek to identify and communicate to others the problems that they face in their daily work lives. New valuable knowledge relevant to their struggles automatically arises in such discussions. Here, however, the success of the discussion depends mainly on the usage of concise and edifying description methods when participants vocalize the bad experiences encountered. Metaphors, analogies, and/or logical schemes are often used to embody new concepts and ideas. 
Combination or Combining represents the conversion process of one piece of explicit knowledge to other pieces of the same type. The method can be interpreted as a process of combining explicit knowledge from different sources, which ultimately leads to the apparition of a new form of explicit knowledge. An example is the process of writing a report.

We search and study different sources of information so that in the end we could compile it into one single report, for example, data on various transactions that would be included in the end into one financial report.

In other words, combining is the process of connecting multiple heterogeneous fragments of explicit knowledge to obtain explicit, systematized, and/or more complex redesigned knowledge.

The transfer of knowledge occurs through various common forms and channels, such as phone conversations, digital networks, documents, and meetings, etc. During knowledge transfers information gets reconfigured by processes of assembling, sorting, logical combining and classification, which at their turn leads to the apparition of new knowledge.

A good example here is the case of a financial analyst who gathers financial data, restructures it, and creates, in the end, a financial report for an organization. The restructured initial data and its analysis become new relevant knowledge for the analyzed company since the report could reveal details that were previously unobserved by the company, even though it had the data available at hand. The new knowledge that appeared from the restructure of the available data could be further used to optimize the decision-making process.

Internalization represents the curious conversion of explicit knowledge into tacit knowledge. Here knowledge is initially captured in written form, but as time goes by this knowledge gets spread among people not in a written form, so the knowledge is progressively becoming tacit. Good examples could be found almost in any organization.

Organizations have clearly defined written rules, but as time goes by the written rules get spread silently - intentionally or not - from one employee that follows them to others. Thus, these initially regulated procedures will become tacit knowledge, as if they were unwritten rules, to begin with.

This is how the so-called "learning-by-doing" process unwraps. Internalization leads to the spread of the explicit knowledge accumulated over the years within the organization. Internalization thus primes the organization for the generation of new valuable tacit knowledge. Hence, it all leads further to the re-creation of the full knowledge cycle. As a result, in the center of the SECI model, we have a spiral that suggests what has been explained earlier, namely the continuity of the managerial cycle with a pronounced quantitative and qualitative growth effect of the general and organization-specific knowledge.

\section{Justifying the supremacy of Knowledge Management in economic and managerial life}

The indisputable supremacy of KM among other corporate resources finds many explanations and justifications on various investigative dimensions. What is without any unnecessary exaggerations truly sensational about KM is the logical and statistical proof that while according to the classical theories other factors' (land, technology, physical labor) marginal effects decrease after a certain point, knowledge not only does not get dropping marginal effects but on the contrary, the rate is increasing at any level. (see Figure 1a)

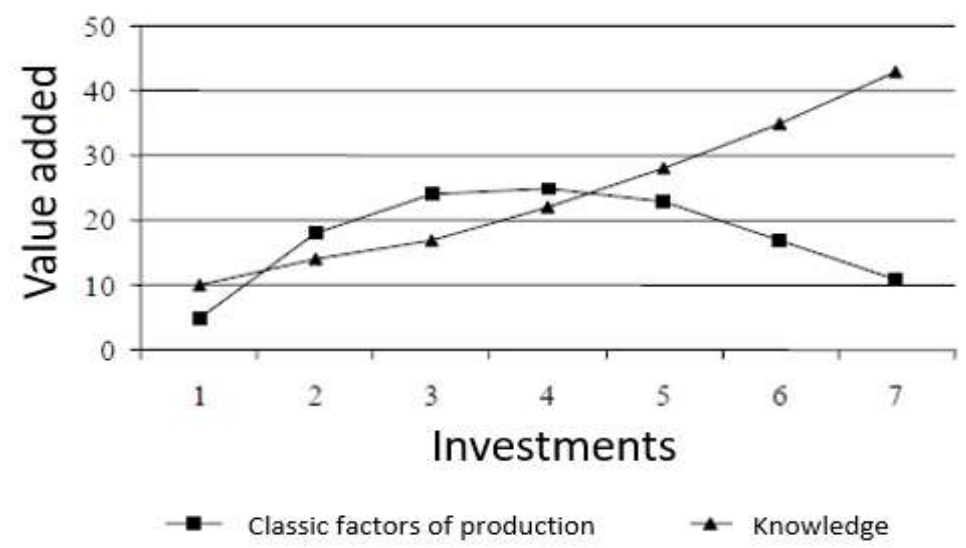

Figure 1a. Marginal effects of economic factors of productivity

The restructuring of human knowledge into perfectly manageable entities that can be managed by various actions and practical tools has spurred the emergence of a new economic managerial theory known as the theory of knowledge management. KM can be defined as the science and art of predicting, managing, 
and especially effectively developing the knowledge of a micro or macroeconomic system in order to fulfill successfully the set objectives.

\section{Macroeconomic value of the KM-SECI Nonaka-Takeuchi management model in the regional development}

If the SECI model as presented above mostly appears to be applicable for individuals and the internal structure of one organization. An extension of the model proposed by the same Nonaka refers to a new idea: generating knowledge from external collaborations. The core vision of the new SECI model is now centered on partner relationships between different organizations (Figure 2).

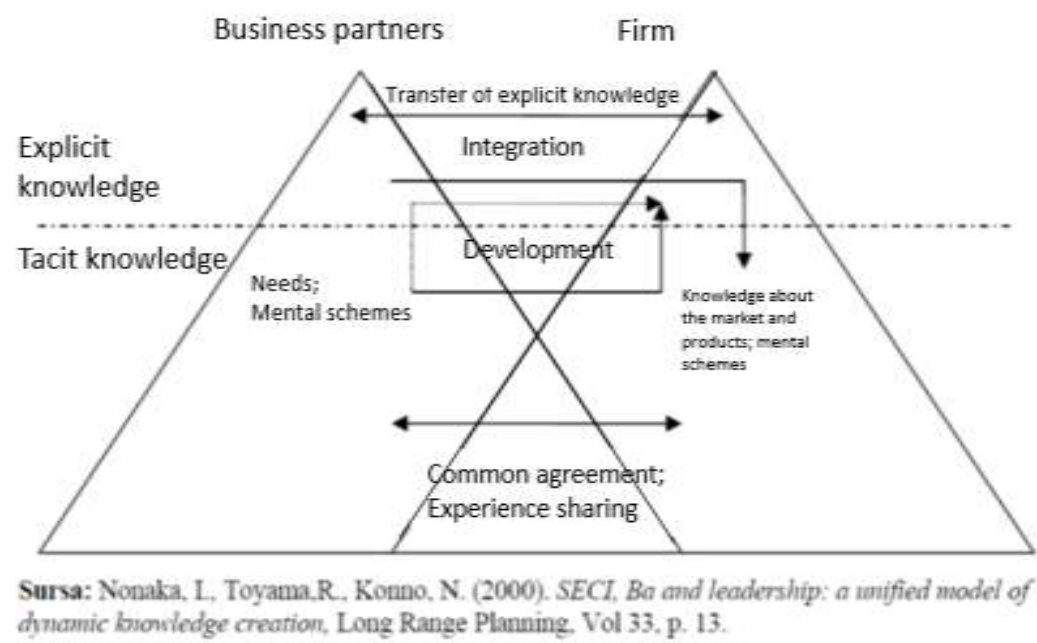

Figure 2. Creating knowledge through partnerships

To allow new knowledge to appear from partnerships it is crucial to build a common NGO-type platform that would have as its goal the sharing of specific experience for achieving a fair mutual understanding. Partners of the two or more collaborating organizations must be put together in common working processes. In this way, their needs and their specific knowledge about the market and products of the respective organizations will become known to the organizations involved in the exchange of experience and will spread among beneficiaries in the form of tacit knowledge.

A classic example here is the client-supplier relationship. The client highlights their needs, and the supplier at their turn shares the possible solutions from the market that they can provide. To improve this knowledge sharing process for both parties, it would be beneficial to have this exchange captured in explicit forms such as documentation, specific rules or basic rules that should be followed in their collaboration.

In this way, the explicit knowledge will be based on the mutual transmission of tacit knowledge, an action that ensures the accurate decoding and the correct understanding of the explicit knowledge transferred between the parties.

Thus, the partnership created between the two organizations will be realized in strict accordance with the ideas of the SECI model. This will lead to the creation of the ascending spiral of their development, the spiral that will designate the logical and functional essence of the theory.

To conclude, all aspects of human lives are dominated by the creative spirit and evolve in the direction imposed by that creative spirit. Today in its development humanity reached the point where the birth of a new type of economy became possible. There is more and more discussion about a knowledge and idea-based economy, in which the key factor of prosperity and job creation is the degree of application of innovation and new technologies in all sectors of the economy.

\section{References}

1. Aceleanu, Mirela \& Chenic (Cretu), Alina. Stefania (2011). Swedish Labour Market Characteristics and Implications on the Organizational Management. Lessons for Romania. Review Of International Comparative Management. 12. $761-769$.

2. Argyris, C.; Schon, D. A. Theory in practice increasing professional effectiveness, San Francisco, Jossey Bass, 1978

3. Andone, I. „Valoarea cunoaşterii în societatea bazată pe competiţie”, în Revista Informatica Economică nr. 1 (25), 2003, pp. 7 - 13

4. Bender, S. Fish, A. „The transfer of knowledge and the expertise: the continuing need for global assignments”, în The Journal of Knowledge Management, 4, 2000, pp. 125 - 137

5. Boin, A., (2012), "Thinking the Unthinkable: The Limits of Traditional Crisis Management and the Necessity for New Approaches", Presentation, First OECD/Swiss Federal Chancellery Workshop on Strategic Crisis Management, Geneva, June 28, 2012.

6. Chenic (Creţu, Alina Stefania (2012). An Analysis of Current Labor Market Developments and Structures in European Union - in Correlation with Labor Market Flexicurity Requirements. Theoretical and Applied Economics. XVIII(2012). 91-108 
7. Malhotra, Y. Why knowledge management systems fail. Enablers and constraints of knowledge management in human enterprises, in Koenig, M.E.D. and Srikantaiah, T.K. (Eds), Knowledge Management Lessons Learned: What Works and What Doesn't, Information Today Inc., Medford, NJ, 2004, pag. 87-112 http://www.brint.org/WhyKMSFail.htm

8. Malhotra, $Y$. „Integrating knowledge management technologies in organizational business processes: getting real time enterprises to deliver real business performance" în Journal of Knowledge Management, Vol. 9, No. 1, 2005, pp. 7-28

9. Mumford, M. D. „Managing creative people: Strategies and tactics for innovation.” în Human Resource Management Review, 10(3), 2000, pp. $313-351$

10. Roja, A., Nastase, M., (2013), Leveraging Organizational Capabilities through Collaboration and Collaborative Competitive Advantage Review of International Comparative Management, Volume 14, Issue 3, July, pp. 359-365

11. Sanchez, M. P. Chaminade, C. Olea, M. „Management of intangible: an attempt to build a theory” în Journal of Intellectual Capital, 1(4), 2000, pp. 312 - 328 